Acta vet. scand. $1968,9,280-283$.

Brief communication

\title{
TIME OF APPEARANCE AND ORIGIN OF SOME POLY- MORPHIC PROTEINS IN SERUM OF PIGLETS
}

For the application of polymorphic serum proteins in the parentage control it is important to know at which time after birth a safe phenotyping can be performed. In swine the presence of maternal (colostral) proteins in the blood during the first days of life may easily lead to an incorrect phenotyping. The purpose of the present study was therefore to establish the time of appearance of some polymorphic proteins commonly used in the parentage control, and to elucidate whether these proteins are due to autosynthesis or whether they are of colostral origin (1). In the latter case the time of disappearance of polymorphic proteins of maternal origin was ascertained.

Sera from 4 Danish Landrace families were taken at birth and at different stages after uptake of colostrum and typed for haemopexin (Hpx), amylase ( $\mathrm{Am})$, ceruloplasmin (Cp) and transferrin (Tf) by means of starch gel electrophoresis $(2,3)$.

The results listed in Table 1 show that haemopexin could not be demonstrated until 3-5 days after birth. The bands were, however, very weak. In samples taken 14 days after birth the intensity of bands was the same as in adults. The haemopexin phenotypes of the $3-5$ days old piglets suggest that this protein is autosynthesized at this age. This is further supported by the fact that haemopexin was demonstrated in 5 colostrum deprived piglets $3-5$ days after birth.

Serum amylase was consistently observed a few hours after uptake of colostrum. In 5 colostrum deprived piglets no amylase could be demonstrated on day 1 clearly showing the colostral origin of the amylase observed. Moreover, the progeny phenotypes were identical to those of the mothers and to the amylase phenotypes observed in colostrum from the respective sows. From Table 1 it appears that after 14 days the progeny possessed phenotypes according to their own genes indicating that amylase components of colostral origin had disappeared. The bands were, however, very weak but increased in intensity so that in $\mathbf{2 8}$ days 


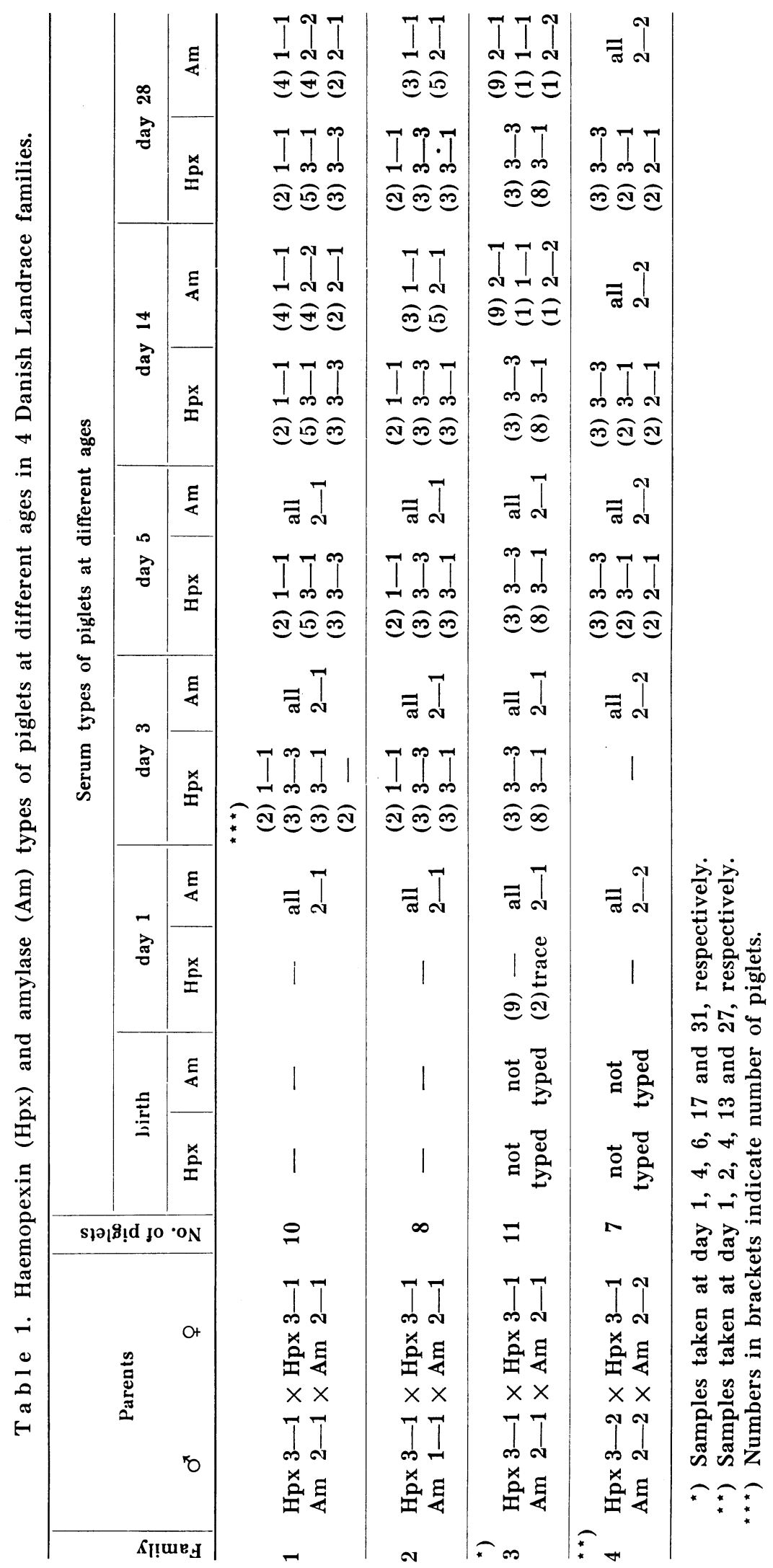



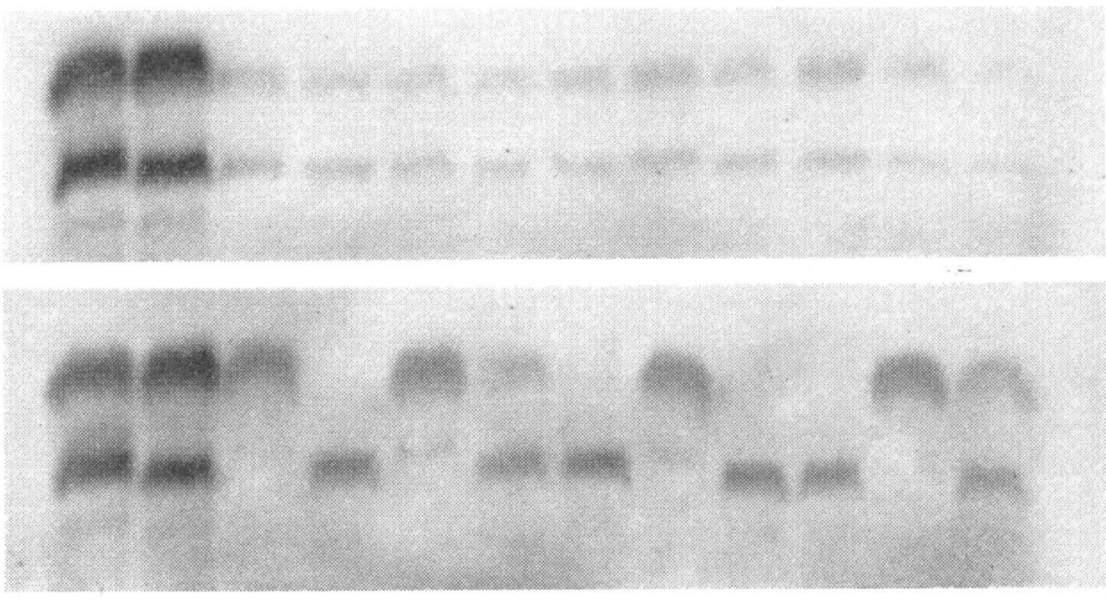

F i g u r e 1. Amylase phenotypes of boar (1), sow (2), and progeny (3-12) of family no. 1 at day 1 (A) and at day 28 (B). A. 1-12: Am. 2-1. B. 1, 2, 6, 12: Am. 2-1; 3, 5, 8, 11: Am 1-1; 4, 7, 9, 10: Am 2-2.

old piglets the bands nearly resembled those of adult animals (Fig. 1).

All pigs investigated were $\mathrm{Tf} \mathrm{BB}$ and $\mathrm{Cp} \mathrm{BB}$. In accordance with the findings of other authors transferrin was observed in the blood at birth. The phenotypical uniformity excluded the possibility of observing maternal transferrin after uptake of colostrum. Ceruloplasmin could not be demonstrated at birth, but appeared in extremely low concentrations during the first $1-3$ days after birth. In 5 colostrum deprived piglets ceruloplasmin was visible in sera taken from 1-3 days old piglets. When the piglets were 14 days old, however, the intensity of bands resembled that of adult sera.

\section{Hesselholt and O. Hansen}

The Department of Physiology, Royal Veterinary and Agricultural College, Copenhagen, Denmark.

\section{B. Panić}

The Department of Physiology, Agricultural Faculty, Beograd-Zemun, Yugoslavia. 


\section{REFERENCES}

1. Hansen, $O$. : Intestinal absorption of macromolecules in newborn pigs. Kgl. Vet.- og Landbohøjsk., Inst. Sterilitetsforskn., Aarsberetn. 1968, 347-364. København.

2. Hesselholt, M.: Haptoglobin polymorphism in pigs. Acta vet. scand. 1963, 4, 238-246.

3. Moustgaard, J. \& M. Hesselholt: Blood groups and protein polymorphism in swine. In Swine in Biomedical Research. Ed. L. K. Bustad \& R. O. McClellan, Frayn Print Co., Seattle 1965.

(Received August 21, 1968). 